
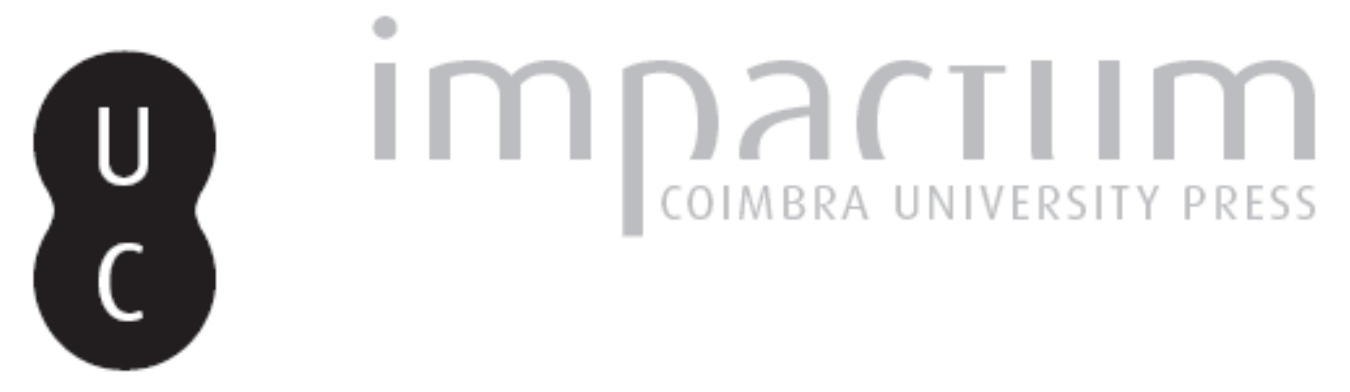

\title{
A estela antropomórfica do Castro de Barrega (Borba da Montanha, Celorico de Basto, Braga)
}

Autor(es): $\quad$ Sampaio, Jorge Davide

Publicado por: Faculdade de Letras da Universidade de Coimbra

URL persistente:

URI:http://hdl.handle.net/10316.2/37745

DOI:

DOI:http://dx.doi.org/10.14195/1647-8657_46_3

Accessed : $\quad$ 26-Apr-2023 10:50:49

A navegação consulta e descarregamento dos títulos inseridos nas Bibliotecas Digitais UC Digitalis, UC Pombalina e UC Impactum, pressupõem a aceitação plena e sem reservas dos Termos e Condições de Uso destas Bibliotecas Digitais, disponíveis em https://digitalis.uc.pt/pt-pt/termos.

Conforme exposto nos referidos Termos e Condições de Uso, o descarregamento de títulos de acesso restrito requer uma licença válida de autorização devendo o utilizador aceder ao(s) documento(s) a partir de um endereço de IP da instituição detentora da supramencionada licença.

Ao utilizador é apenas permitido o descarregamento para uso pessoal, pelo que o emprego do(s) título(s) descarregado(s) para outro fim, designadamente comercial, carece de autorização do respetivo autor ou editor da obra.

Na medida em que todas as obras da UC Digitalis se encontram protegidas pelo Código do Direito de Autor e Direitos Conexos e demais legislação aplicável, toda a cópia, parcial ou total, deste documento, nos casos em que é legalmente admitida, deverá conter ou fazer-se acompanhar por este aviso.

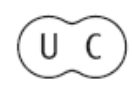




\section{CONIMBRIGA}

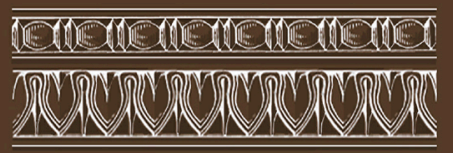

INSTITUTO DE ARQUEOLOGIA

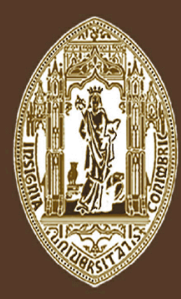

VOLUME XLVI - 2007

FACULDADE DE LETRAS UNIVERSIDADE DE COIMBRA 
Jorge Davide SAmPaio

Parque Arqueológico do Vale do Côa

Câmara Municipal de Celorico de Basto (Colaborador)

\section{A ESTELA ANTROPOMÓRFICA DO CASTRO DE BARREGA (BORBA DA MONTANHA, CELORICO DE BASTO, BRAGA) "Conimbriga" XLVI (2007) p. 53-71}

RESUmo: Apresenta-se o estudo de uma estela antropomórfica descoberta no Castro de Barrega, um povoado da Pré-história recente localizado no concelho de Celorico de Basto. Este monumento apresenta uma temática decorativa clássica, formalmente similar às esculturas congéneres do território peninsular: anatomicamente encontra-se representado o rosto humano, com a boca, nariz, braços e mãos, e como elementos de adorno apenas os colares; não se encontram representados diadema nem armas. Trata-se de uma escultura de granito apenas gravada no anverso e sem qualquer tratamento tridimensional. Apesar das semelhanças com os monumentos estremenhos, esta estela parece contribuir para o já amplo polimorfismo que tem dificultado uma classificação tipológica mais precisa.

Por outro lado, este monumento assume particular importância pelo seu aparente contexto arqueológico, o qual ajudará certamente a uma melhor caracterização crono-cultural, representando, ainda, um contributo valioso para a sistematização dos grupos com uma a heterogeneidade conceptual que tanto caracteriza o panorama peninsular.

RÉSUMÉ: Nous présentons l'étude d'une stèle anthropomorphe découverte dans le site fortifié protohistorique de «Castro de Barrega» qui appartient dans Celorico de Basto.

Cette pièce est de thématique décorative classique, comparable à des sculptures congénères de la péninsule ibérique. Est figurée la partie supérieure d'un corps humain, par sa bouche, son nez, ses bras et ses mains, ornée de colliers, mais où diadème et armes sont absents. Une 
seule de ces faces est gravée et la stèle ne présente aucun traitement en trois dimensions. Malgré l'existence de points communs avec des stèles estremenhas, elle augmente encore le polymorphisme qui a rend difficile une classification typologique plus précise.

L'intérêt de cette pièce est de posséder un contexte archéologique qui aidera sûrement à obtenir une meilleure caractérisation chrono-culturelle, contribuant ainsi à la systématisation des groupes dont l'hétérogénéité conceptuelle est une des caractéristiques du panorama péninsulaire. 


\section{A ESTELA ANTROPOMÓRFICA DO CASTRO DE BARREGA}

(Borba da Montanha, Celorico de Basto, Braga)

\section{Introdução}

Em finais de 2005, no decurso de um registo arqueológico levado a cabo na freguesia de Carvalho, no âmbito de trabalhos associados à elaboração da Carta Arqueológica de Celorico de Basto, fomos informados por um residente local ${ }^{1}$ da existência de uma "pedra redonda com uma espécie de mãozinhas desenhadas". O informador fez esta descoberta casualmente há cerca de dois anos, numa área recentemente livre do espesso manto arbustivo que se desenvolvia no denominado Castro de Barrega, localizado na vizinha freguesia de Borba da Montanha. O achado foi transportado no momento da descoberta, com o auxílio de um rebocador, dado o seu peso, e depositado ao ar livre em terreno particular. A partir destas informações - sumárias, mas elucidativas - apercebemo-nos de imediato do tipo de achado, da sua importância e raridade, pelo que a visita ao local de depósito foi feita de imediato (tendo-nos acompanhado o Dr. Pedro Gonçalves ${ }^{2}$, que tem colaborado nos trabalhos de campo e pesquisa bibliográfica, referentes ao projecto acima referido), confirmando-se as informações orais e as suspeitas preconizadas.

Posteriormente, com o apoio da Câmara Municipal de Celorico de Basto e do autor da descoberta, procedemos ao transporte e acondicionamento em local apropriado do monumento, tendo decorrido, já no início de 2006, os trabalhos de limpeza e levantamento arqueológico.

1 Sr. Celestino Magalhães, a quem agradecemos a informação.

2 Responsável pelo inventário do Património Arquitectónico da Câmara Municipal de Celorico de Basto, associado à revisão do Plano Director Municipal. 
Apesar deste estudo incidir essencialmente sobre aspectos de cariz descritivo, procurou-se enriquece-lo, embora que de forma sumária, com aspectos em torno dos contextos crono-culturais conhecidos, antecipando-nos, desta forma, a um estudo de conjunto, esse sim, mais abrangente, que será certamente realizado a breve trecho.

\section{Localização e quadro geográfico}

A estela antropomórfica foi detectada no sector topograficamente mais elevado do monte que se ergue imediatamente a nascente da aldeia de Barrega (junto de afloramentos graníticos que se dispõem em torno de uma instalação eléctrica devoluta), designado de Castro de Barrega, ou Roda da Santinha, como é conhecido popularmente. Embora a extensão total do local compreenda duas freguesias, a detecção foi feita em área administrativa da freguesia de Borba da Montanha (concelho de Celorico de Basto, distrito de Braga). Acede-se ao local a partir da estrada municipal n. ${ }^{\circ}$ 616, que liga a freguesia de Fervença à de Borba da Montanha, respectivamente. No cruzamento de Poça de Pedra, segue-se a estrada da esquerda que liga aos lugares de Barrega e de Lameira (Rego). A escassos metros daquela primeira aldeia deve atalhar-se por um caminho à direita (junto a uma capela) percorrendo-se o restante trajecto em caminho carreteiro até ao topo do monte. Alternativamente, o percurso poderá ser feito a partir da estrada de terra batida que liga a freguesia de Carvalho (a partir do cemitério) à serra do Viso.

As coordenadas geográficas referentes ao local exacto da descoberta do monumento são as seguintes 3 :

Latitude: $41^{\circ} 23^{\prime} 27^{\prime \prime}$ N; Longitude: $08^{\circ} 04^{\prime} 16^{\prime \prime}$ E; Altitude: $744 \mathrm{~m}$

Geomorfologicamente, o relevo do território concelhio é marcadamente heterogéneo, resultado de factores geológicos (aos níveis tectónico e litológico), os quais criaram quer as áreas de pendor bastante acentuado, associadas a áreas planálticas, quer os vales, ora alcantilados, ora abertos, com predominante orientação para o rio Tâmega (PEREIRA, 1989).

Do ponto de vista orográfico, o Castro de Barrega é um cabeço localizado entre o limite do planalto da Lameira que se desenvolve

3 Carta Militar de Portugal, escala 1: 25 000, folha n. ${ }^{\circ}$ 86: Celorico de Basto,

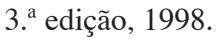


a Norte, a serra do Viso a NE e a serra de Calvelo a Poente, marcando uma posição de destaque na margem esquerda do vale, aberto, da rib. ${ }^{\text {a }}$ de Sta. Natália, afluente do rio Tâmega (Fig. 1).

O local em causa apresenta uma morfologia oval, sendo a área em torno da qual foi detectado a estela, circular e topograficamente aplanada, orientando-se uma pequena plataforma para poente e outra para Norte, local que proporciona melhores acessos, uma vez que as restantes vertentes apresentam declive acentuado. A limpeza recente da área mais elevada evidenciou dois anéis artificiais e taludes pronunciados, bem como possíveis vestígios da implantação de uma muralha no sector Norte, indícios que apontam para um local fortificado, de carácter habitacional ${ }^{4}$.

O vale é caracterizado por espessos depósitos de cobertura holocénicos (PEREIRA, 1989), que definem a excelente aptidão agrícola deste espaço, à qual não é alheia a abundante rede hidrográfica. O seu escoamento é feito a partir de inúmeras linhas de água com orientação para a referida ribeira, a qual se encaminha para a bacia hidrográfica do Tâmega (sub-bacia do rio Douro).

Do ponto de vista geológico, o território de Celorico de Basto caracteriza-se essencialmente por dois modelos litológicos: o granito ${ }^{5}$ e o xisto e metagrauvaques ${ }^{6}$. O primeiro regista as maiores ocorrências, abrangendo largas faixas do território concelhio, aflorando em caos de blocos, enquanto que o segundo se ajusta a dois sectores: a Este e a Sul, ao longo do rio Tâmega.

O sítio do achado localiza-se dentro do $1 .^{\circ}$ modelo, constituído pelos seguintes litótipos: granodioritos e raros quartzodioritos biotí-

4 O sítio fora já referenciado pelo Padre Magalhães Costa em 1942 (Diário do Minho), pelo Eng. ${ }^{\circ}$ Ilídio Araújo, no início dos anos 60 (Jornal regional Ecos da Montanha, Celorico de Basto), e por Armando Coelho Ferreira da Silva (Silva, 1986). É, porém, apenas no início da década de 2000 que se levam a cabo as prospecções sistemáticas no âmbito da Carta Arqueológica concelhia, trabalhos que permitiram caracterizar melhor a ocupação do sítio do ponto de vista cronológico, tendo ainda sido detectada alguma arte rupestre).

5 Constitui a principal mancha litológica, destacando-se o granito porfiróide de grão grosseiro, de duas micas, essencialmente biotítico, classificado como granito de Amarante e de Celorico de Basto.

6 A segunda litologia, classificada como Unidade de Vila Nune, envolve, nos sectores E e S, as massas graníticas. 
ticos, suporte sobre o qual foi produzido o exemplar de arte escultórica em estudo.

\section{Metodologia dos trabalhos de limpeza e levantamento}

Face às condições de depósito do monumento (que permaneceu ao ar livre e junto a uma estrada municipal durante dois anos, correndo risco de ser furtado e de sofrer erosão acentuada), levamos a cabo o registo fotográfico no local e o transporte para a Casa do Cabo (freguesia de Carvalho), tendo ficado provisoriamente ao cuidado do Sr. António Coelho Santos, até estarem criadas as condições para exposição no Núcleo de Arqueologia deste concelho.

Já devidamente acondicionada, procedemos, no dia 1 de Abril do ano transacto, de forma breve, ao trabalho de limpeza dos planos que continham escassos líquenes, e ao registo fotográfico e de desenho, ambos auxiliados por iluminação artificial. O decalque directo foi realizado à escala 1:1, sobre "plástico de cristal".

O levantamento foi orientado por Rosa Jardim (do Centro Nacional de Arte Rupestre), tendo participado, para além do signatário, Bruno Figueira, Pedro Gonçalves e Winde Martens. O tratamento digital do desenho foi igualmente levado a cabo por Rosa Jardim.

\section{Análise tecno-morfológica}

A estela antropomórfica de Barrega foi encontrada numa zona de granodioritos e raros quartzodioritos biotíticos, inserindo-se na grande mancha de granito porfiróide de grão grosseiro, de duas micas, essencialmente biotítico, que predomina no concelho. Este tipo de litologia ocorre com pouca frequência no ambiente geológico circundante, sendo esta a área em torno da qual se localiza a maior formação, aflorando depois em manchas muito localizadas nas freguesias de Caçarilhe, Rego e Arnoia. Excepto as grandes massas que afloram nesta área, é possível encontrar com relativa facilidade, soltos, suportes similares ao que foi gravado, facto que reforça a ideia do monumento ter sido produzido com matéria-prima local, e ali ter sido utilizado e abandonado. Por outro lado, tal tese sai reforçada com base na argumentação do contexto arqueológico, a que já nos referimos e trataremos em detalhe adiante. Não 
obstante, o estudo petrográfico comparativo que está a ser realizado à peça bem como a uma amostra de afloramento do local da descoberta poderão clarificar a origem daquele material pétreo.

A estela de Barrega é um suporte sub-rectangular (Figs. 2 e 3), apresentando as seguintes medidas: altura total: $79 \mathrm{~cm}$; largura no topo: $59 \mathrm{~cm}$; diâmetro (parte mesial): $25 \mathrm{~cm}$. A base tem uma largura irregular, facto que se deve a uma fractura no canto inferior direito (verosimilmente antiga e verificável a partir de um ligeiro boleamento das arestas), que não afectou o corpo inscultórico. Observa-se uma outra fractura, menos acentuada, no bordo distal, sobre a cabeça, não tendo, contudo, interferido com os sulcos delimitadores desta forma. De resto, e excepto algumas nuances suaves esbranquiçadas localizadas sobre o corpo iconográfico no sector superior do suporte (provocadas durante o transporte na altura da descoberta) o estado de conservação da composição gravada é boa, facto que também se deve à excelente qualidade da gravação e à ausência de deslocações sumárias a que este tipo de achados são normalmente sujeitos.

Ao contrário dos monumentos tipo estátua-menir, em que geralmente se verifica uma certa antropomorfização prévia do suporte, as estelas antropomórficas ${ }^{7}$ remetem para a utilização do suporte enquanto receptor iconográfico, não existindo uma preocupação na obtenção de um corpo escultórico tridimensional. No caso concreto, o tratamento prévio à gravação verifica-se apenas no anverso, a partir de um polimento ténue sob a metade superior gravada, que é visivelmente reforçado na sua metade inferior (a não gravada). O objectivo deste polimento poderá estar relacionado com o embelezamento do suporte, ou com a necessidade de extrair ou dissimular possíveis acidentes e irregularidades da superfície. Não obstante, estas ideias tornam-se algo inverosímeis, ao observar-se que o sector gravado é aquele que se apresenta mais defeituoso e nem por isso teve o mesmo tratamento que o oposto. De resto, e excepto este tratamento, o bloco parece já ter sido obtido com esta morfologia, ou, pelo menos, similar (até porque os pla-

7 A denominação proposta por D’ANNA (1977) define a estela antropomórfica como um superfície plana, na qual a decoração se dispõe numa das faces. A definição incluída no Dictionnaire de la Préhistoire (LEROI-GOURHAN, ed., 1988: 996-997) caracteriza este tipo de monumento da seguinte forma: "Stèle: bloc de pierre assez plat, dont la hauteur ne dépasse généralement pas $1 \mathrm{~m}$., et de une des faces porte une figuration humaine schématique". 
nos laterais ainda exibem alguns acidentes naturais e algumas irregularidades não antrópicas).

Apenas a metade superior do suporte foi gravada, levando a admitir uma possível fixação ao solo, a partir da outra metade. A técnica utilizada na obtenção das gravuras parece ter sido a mesma: picotagem e abrasão (produzindo sulco em $\mathrm{U}$ ), eventualmente com recurso a instrumento metálico (?), embora as mãos e braços remetam para um utensílio, no mesmo material, mas mais pontiagudo, pelo sulco profundo que apresentam (em V). Aliás, de toda a composição, as mãos e braços são os elementos que melhor são tratados, dando a ideia de uma preocupação estético-simbólica subjacente, facto que também parece ser realçado pela eventual posição invertida de uma das mãos. A existência de dois pequenos sulcos que se prolongam a partir da extremidade de dois dedos da mão esquerda, parecem indicar o esboço prévio da figura, sem recorrer à técnica de picotagem. A profundidade dos sulcos não ultrapassa os $5 \mathrm{~mm}$, excepto ao nível das mãos e colares, onde atinge valores superiores.

O monumento não apresenta decoração que sugira a tridimensionalidade (à excepção de um sulco gravado lateralmente, que não parece antrópico), nem decoração no reverso. Não foram detectados vestígios de pintura na totalidade do corpo.

O conjunto figurativo foi elaborado, como já referimos, em torno da metade superior do suporte (a mais larga), tendo sido gravada a parte superior frontal de uma figura humana estilizada, e atributos complementares, caracterizada pelos seguintes elementos: cabeça, braços, mãos e elementos de adorno (colares). Aparentemente dissociada do conjunto foi gravada uma "covinha", pouco profunda.

$\mathrm{O}$ anverso pode ser dividido em duas secções: a que se apresenta gravada (alt. $43 \mathrm{~cm}$ x $57 \mathrm{~cm}$ de larg.), na metade superior, e a que não tem qualquer gravura, na metade inferior (alt. $28 \mathrm{~cm}$ x $53 \mathrm{~cm}$ larg.), talvez para a sua fixação ao solo.

Apesar de poucos, são conhecidos alguns paralelos tipológicos e morfológicos para este monumento, os quais exibem os membros inferiores [estelas estremenhas da Serra de Gata, nomeadamente o Ídolo de Cambroncino, o Ídolo de El Cerezal e o Ídolo de Ciudad Rodrigo (SEvillano SAn José, 1991: 104-106). Estes, a desempenharem a mesma função, colocariam os membros sob o solo (dada a sua proximidade com a base das peças), ou então estariam simplesmente suportadas por elementos pétreos, ou outros, perecíveis. Almagro-Gorbea 
defende que esta ausência implica uma inclusão daquela área do suporte na própria composição iconográfica. Quando, pelo contrário, os membros aparecem representados, o espaço passa a desempenhar o papel de mero suporte (AlMAGRo GoRBEA, 1977: 198).

Assim, a composição é definida na parte superior, $12 \mathrm{~cm}$ abaixo de um pequeno desmantelamento (verosimilmente antigo) do bordo, por uma rosto humano esquemático, caracterizado por dois traços curvos (mas que não chegam a unir-se, conformando, em círculo ou semicírculo, a cabeça), que delimitam as faces e enquadram os restantes motivos: dois olhos, obtidos por dois sulcos pequenos e pouco profundos; um nariz em $\mathrm{V}$ aberto com um traço pouco nítido, que arranca sensivelmente do nível dos olhos até ao limite das faces; e uma boca igualmente pouco definida, representada apenas por um traço, levemente côncavo e que marca, no seguimento das linhas faciais, a parte inferior do rosto. Apesar da parte superior se apresentar algo degradada, como já referido, não nos parece ter sido gravado o traço correspondente à arcada supracilar, que por vezes aparece representada, com o objectivo de definir a cabeça. Não deixa de ser curiosa a ausência de «diadema», elemento gravado em mais de $90 \%$ deste tipo de estelas. Por outro lado, a ausência de uma parte do sector superior direito do suporte não legitima a ausência daquele acessório, já que este está sempre associado à cabeça, verificando-se, no caso concreto, que a linha que delimita a cabeça (do lado esquerdo) tem um fim e um início nítido, sem sequer ser interrompida pelo referido desmantelamento. Ou seja, a ter existido, estaria dissociado da cabeça, constituindo caso raro no contexto peninsular ${ }^{8}$. Entre o arranque do braço direito (referimo-nos sempre à óptica do observador) e a linha da face, e um pouco acima do arranque dos elementos de adorno, localiza-se um sulco, de características semelhantes aos que representam os olhos. A presença deste elemento não encontra qualquer enquadramento, pelo que se tratará de um momento de gravação prévio, na tentativa de localizar espacialmente os olhos, ou mesmo de um momento posterior, na tentativa de redefinição ou acréscimo de outros componentes.

Lateralmente foram gravados dois braços em traço profundo e cuidado, claramente evidenciados, à semelhança dos elementos de adorno a que nos referiremos adiante. $\mathrm{O}$ arranque é feito ao nível médio das

8 A estela de Ciudad Rodrigo 1 apresenta um diadema, que apesar de estar dissociado da cabeça, se encontra parcialmente ligado a um dos braços. 
faces, a partir de dois sulcos abertos que se prolongam de forma regular ao longo daqueles elementos, sendo que o braço esquerdo apresenta um estrangulamento ao nível da articulação, alargando depois para descrever a mão, de cinco dedos bem definidos que repousam sobre o ventre. O braço esquerdo descreve uma curva regular, terminando sensivelmente ao mesmo nível que o oposto, numa mão cuja face interna e côncava parece estar voltada ao contrário, talvez em atitude de oferta de algo, ou apenas um gesto identitário, repousando igualmente sobre o ventre. Por outro lado, a ordem de grandeza dos dedos nela representados indicam uma posição contrária, ou seja, a normal. A única certeza que transparece da observação deste elemento é a de uma preocupação efectiva no destaque deste braço, evidenciada não só pela morfologia (mais alongada) do braço, como pela demarcação da linha proximal da palma da mão. O gravador quis realçar claramente e definir este braço, gravando-o de uma forma mais figurativa, menos esquemática do que o oposto, conferindo ao todo um significado especial, a que nos referiremos mais adiante. Resta, a este respeito, referir que no já vasto conjunto de monumentos congéneres não se encontram paralelos para a morfologia desta mão. Aliás, na esmagadora maioria dos casos, as mãos não se apresentam tão expressivas.

A finalizar a composição, destacam-se os colares, atributos habituais nas estelas-menires e nas estelas antropomórficas, que tradicionalmente definem a feminilidade do monumento ${ }^{9}$. São no total 5 traços algo cavados, de profundidade e largura idênticos às mãos e braços. Arrancam a partir de duas linhas contíguas e horizontais (com $12 \mathrm{~cm}$ de comprimento), localizadas sob a parte final das linhas que delimitam o rosto, prolongando-se em semicírculo, entre os braços e as mãos na zona peitoral.

É de salientar a forma como o conjunto de colares é unido na sua parte superior, já que normalmente as linhas se apresentam soltas ou

9 Não obstante, a tese generalizada sobre estes atributos, verosimilmente femininos, tem ficado comprometida com achados onde os atributos masculinos se lhes associam (falos e armas). Veja-se, a título de exemplo, o monumento de Faiões, em Chaves (Almeida e Jorge, 1979: 19), o de A-De-Moura, na Guarda (Silva, 2000), e o de Hérnan Pérez VI, em Cáceres (Bueno Ramirez, 1987: 454-455). Numa hipótese muito remota, em alguns dos casos, os atributos masculinos podem ter sido gravados em momentos posteriores, sem qualquer preocupação na manipulação dos contornos que haviam sido produzidos anteriormente. A utilização destes atributos poderia, apenas ocasionalmente, em momentos de particular importância, caber aos homens. 
prolongam-se de forma a unir-se com o diadema. Aliás, em muitos casos a própria união dos dois resulta numa solução tão perfeita que acaba por conformar o próprio rosto (Pobledillo de Gata, Granja de Toninuelo, entre outros).

\section{Aproximações gráficas}

A contextualização da estela do Castro de Barrega apresenta alguns problemas, decorrentes da ausência de paralelos geográfica e graficamente próximos, os quais lançam a questão sobre as tradições autóctones e os naturais vínculos culturais com outras áreas peninsulares e mesmo extra-peninsulares. Trata-se, pois, de uma variante regional, geograficamente distante daqueles que têm sido considerados os núcleos centrais dos grupos artísticos, maioritariamente localizados na parte ocidental da Península Ibérica. Um dos conjuntos mais homogéneos localiza-se na região estremenha de Las Hurdes e Sierra de Gata (Cáceres), estendendo-se ainda para Norte já na província de Salamanca (Ciudad Rodrigo), o qual tem constituído referência no estudo comparativo deste tipo de estatuária. Dentro deste conjunto tipológico, denominado de "Hurdes-Gata" (BuENO RAMIREZ, 1987), encontramos alguns exemplares (não exactamente paralelos, mas com semelhanças formais e gráficas aproximadas) para o monumento de Barrega: estelas de Agallas (Salamanca) e Hernán Pérez I e IV (Cáceres). Aquela, apesar de classificada como estátua (pelo tratamento gráfico tridimensional) (BUENO RAMIREZ, 1995: 101) apresenta praticamente as mesmas características iconográficas: ausência de cinturão ritual e toucado radial, ao contrário destas que ostentam estes acessórios, embora mantenham as mesmas características anatómicas.

O monumento de Robledillo de Gata (Cáceres) (BuEno RAMIREZ, 1990: 100) é marcado pela ausência de membros inferiores e de cinturão, à semelhança do de Barrega, estando, por sua vez representado o diadema. Já os de Cambroncino (Cáceres) e Ciudad Rodrigo I (Salamanca), caracterizam-se pela presença de membros inferiores e diadema, estando ausente o cinturão. Referência ainda para um monumento de características semelhantes na província de Cáceres: ausência de pés e de cinturão, diferenciando-se apenas pela presença de diadema e de uma linha horizontal semelhante às que aparecem representadas em alguns monumentos do grupo de Hernán Pérez. 
No entanto, a mais importante concentração de estelas e estátuas-menires antropomórficas localiza-se no Cabeço da Mina (Moncorvo) (JoRGE, 1999: 137). Neste conjunto (caracterizado por uma dissemelhança ao nível do suporte, dimensão e decoração) cabem algumas semelhanças e diferenças relativamente ao monumento em questão: por exemplo, em relação àqueles exemplares não figuram armas nem sexo, nem pés, à semelhança deste, estando, naqueles casos, presentes os atributos complementares (cinturão) e ausência de boca (à excepção de um único caso). Assim, a tentativa de aproximação gráfica e tipológica da estela de Barrega a um dos exemplares do conjunto do Cabeço da Mina (o Tipo IIIC parecia o mais adequado) fica comprometida pela ausência, quase exclusiva, da componente anatómica e pela presença (eventual) de cinturão, para além dos suportes caracterizados por uma morfologia tendente para o tipo estela-menir e não estela antropomórfica (JORGE, 1999: 139), não permitindo a sua aproximação. Os exemplares do Crato e de Nossa Senhora da Esperança (Alentejo) não apresentam pés gravados, à semelhança do exemplar de Barrega, encontrando-se, porém, ausentes a boca e as mãos, características que, tal como às que nos temos referido, devem obedecer a variantes regionais, inseridas num contexto de influências extrínsecas, evidentes nos grupos citados. Veja-se ainda o exemplar de Quinta do Couquinho (Trás-os-Montes), que também não revela membros inferiores, nem mãos, mas onde aparece representada a boca.

Não obstante a dificuldade que emerge face à variedade gráfica disponível, devemos concluir que os paralelos conceptuais mais directos para o monumento do Castro de Barrega se encontram no tipo B3-B de Almagro Gorbea (1993: 132), claramente no grupo das estelas antropomórficas estremenhas.

\section{Contexto arqueológico regional e cronologia}

Apesar da esmagadora maioria dos monumentos descobertos até à data resultarem de contextos sem outra ambiência arqueológica, conhecem-se algumas versões gráficas similares com precedentes megalíticos no seio da Península Ibérica, as quais têm valorizado a sua origem neste fenómeno (GonzÁlez Cordero \& Alvarado GonZalo, 1986: 261; BuENO RAMIREZ, 1995: 119). Tem sido comummente aceite o recuo destas manifestações ao III. $^{\circ}$ milénio a. C., e a sua evolução, sob diversos 
aspectos distintivos, até à Idade do Bronze (Bueno RamiREZ, 1987: 453). As versões gráficas de ambos os períodos são marcadamente diferentes, já que, enquanto que numa primeira fase se produzem monumentos pouco evoluídos em termos decorativos e que tendem à antropomorfização do personagem representado, numa fase posterior merecem atenção as armas associadas a figuras humanas representadas em clara manifestação de poder (veja-se, por exemplo, os monumentos de Longroiva, Tabuyo del Monte, Hernán Pérez VI, etc.).

O grupo de estelas antropomórficas de Hernán Pérez, para o qual julgamos existirem algumas semelhanças com a de Barrega, tem sido atribuído ao Calcolítico (AlMAGRo GoRBEA, 1993: 123-139). Esta ideia tem sido matizada com base nos dados obtidos há pouco mais de uma década na região da Galiza onde formam detectados pequenos ídolos e estátuas de módulo superior em pleno contexto dolménico, bem como menires decorados com motivos antropomórficos, ao ar livre.

Para além do exemplar de Axeitos (La Coruna) (FABREgAS VALCARCE, 1991: 313) merecem destaque algumas peças provenientes daqueles monumentos funerários (dólmen da Parxubeira, em La Coruna) (RODRIGUEZ CASAL, 1989, 1992) às quais podemos claramente associar - pelas características morfo-técnicas, o ídolo descoberto no início dos anos 90 no planalto da Lameira (Rego, Celorico de Basto), a escassos $5,5 \mathrm{~km}$ para Norte do Castro de Barrega. O seu enquadramento arqueológico remete para uma área caracterizada por vários grupos de mamoas (Povoação, Arranhadouro, Travessa, Vacaria, Vale do Abade, Urgeirais) ${ }^{10}$, de fossas abertas no saibro (Vale de Vinho, Serrinha, Lameira, Arranhadouro, Pedroso e Areeiro) e afloramentos gravados essencialmente com covinhas (Tapada, entre outros localizados a maior distância). Os grupos de tumuli são, de uma forma geral, atribuíveis ao Calcolítico e/ou Idade do Bronze, sendo que para algumas daquelas estruturas escavadas no substrato saibroso contamos com datações absolutas que medeiam entre o Neolítico Médio e a Idade do Bronze final (SAMPaio e Faustino, 2002: 36; BetTencourt et al. 2002: 191). Apesar da gramática decorativa se apresentar, tanto naquelas situações como nesta, de formas diferentes (já que o trato gráfico pode apenas contemplar o suporte antropomórfico, ausente de qualquer gravação, como defini-lo a partir da inclusão de atributos anatómicos), repete-se a

10 Nenhuma delas foi intervencionada até à data, tendo algumas sido objecto de escavações clandestinas durante a 2 . $^{\text {a }}$ metade do século XX. 
morfologia, (que pode variar na maior ou menor conotação antropomórfica) e o volume.

Apesar da dificuldade em poder estabelecer paralelos entre este tipo de manifestação antropomórfica e as estelas de volumetria superior, alguns autores atribuem semelhanças ao nível dos recursos gráficos entre estes conjuntos e as estelas estremenhas e as placas alentejanas (BUENO RAMIREZ, 1995: 79-80).

A contextualização arqueológica deste achado, apesar de evidente não é de todo segura. A sua condição de jazida é clara, ao ter sido detectada num sítio arqueológico, mas a ausência de um contexto estratigráfico afasta qualquer alternativa para uma correcta inserção cronológica. Assim, devemos valorizar o ambiente arqueológico do qual faz parte, encarando os limites existentes, mas onde cremos haver lugar para, a partir de alguns argumentos importantes, tentar propor o local onde teria originalmente sido implantado (capítulo 5). Apesar de não ser crível a descoberta de um monumento análogo em contexto estratigráfico (em intervenções arqueológicas futuras) será importante definir as fases de ocupação do sítio facilitando assim as inferências sobre os aspectos crono/culturais.

Apesar de descrito parcialmente no capítulo posterior julgamos importante reter aqui duas ideias acerca deste assunto: primeiramente o contexto parcial de âmbito local, no qual encontramos um sítio com características de povoado fortificado (taludes no sector Norte), onde abundam cerâmicas de fabrico manual, sem qualquer decoração (fragmentos de bojo, bordos e bases planas), elementos de moagem manual, e a recém descoberta arte rupestre ${ }^{11}$ (trata-se de um volumoso bloco de granito, onde foram gravadas duas armas de índole ainda mal definida nesta fase dos estudos, mas com evidente cronologia avançada em relação ao monumento objecto de estudo). Em segundo lugar o contexto de âmbito mais alargado, caracterizado por povoados de cronologia ampla (que medeiam entre o Neolítico Final e a Idade do Bronze) e necrópoles megalíticas. Destacamos o povoado do Monte de S. Lourenço, localizado a 1,2 km para SW e a necrópole de Outeiro de Mamo (conjunto de quatro tumuli destruídos há cerca de 5 anos) localizados a 1,2 km

11 A prospecção fina levada a cabo no local da descoberta do monumento em questão, no mês de Agosto, pelo signatário e pelo Dr. Pedro Gonçalves, resultou na identificação deste bloco gravado. Apesar do seu registo gráfico já ter sido por nós realizado, aguarda-se para breve a sua publicação. 
a SW do Castro de Barrega, a escassos metros da veiga que se espraia na base do já referido Monte de S. Lourenço (onde, aliás, detectamos recentemente um conjunto cerâmico pré-histórico aparentemente associado a um segmento de círculo em sílex). À mesma distância, mas para Norte, localiza-se, uma outra necrópole, composta por 3 tumuli. De resto, os achados sucedem-se em todos os quadrantes mas a distâncias que ultrapassam aqueles números. As teses (devidamente contextualizadas) sobre a associação directa destas estelas aos monumentos megalíticos não parecem fazer sentido no caso concreto. A distância entre ambos, apesar de curta, é desvalorizada pelo contexto arqueológico local a que já nos referimos. No entanto, faz sentido falar de contemporaneidade, já que os tumuli em questão apresentam características formais que remetem de uma forma geral para o Calcolítico (e em alguns casos para o período subsequente). Apesar da ausência de elementos de diagnóstico que possam caracterizar o local da descoberta da estela, é possível que tal tenha sido ocupado durante III. ${ }^{\circ}$ milénio a. C. e que as necrópoles de Outeiro de Mamo ou mesmo as de Penícia tenham sido os locais de enterramento dos seus mortos.

\section{Função e significado}

Os inúmeros autores que ao longo do século passado se dedicaram ao estudo deste tipo de estatuária, têm sido unânimes na atribuição de um certo carácter funerário, nunca deixando, porém, de expor a dificuldade na sua caracterização, já que as condições de jazida são, em regra, desprovidas de qualquer enquadramento arqueológico, quer funerário, quer habitacional. No entanto, algumas descobertas têm vindo a reforçar aquela primeira tese. Exemplos bem conhecidos são o conjunto de estátuas-menires de Hernán Pérez (Cáceres) que aparece associado a sepulturas tipo cista (AlmAGRo BASCH, 1972: 91) ou o monumento de El Cerezal I (na mesma região) (SEvillano SAN José, 1982: 166; BUENO RAMIREZ, 1987: 454-455). As estelas em território francês às quais tem sido atribuída uma cronologia mais recuada (Neolítico médio) (ESCALON DE FONTON, 1962) foram igualmente localizadas junto a pequenos túmulos individuais.

Porém, o próprio cariz funerário que tem sido comummente defendido tem levantado e continua a levantar questões prementes, mas de uma quase impraticável resolução: a imagética funerária assenta na gra- 
vação esquemática e simbólica do personagem falecido, ou de uma divindade tutelar? As conjecturas podem também alargar-se à representação de espíritos protectores, deuses ou deusas ou mesmo de determinado protagonista divinizado, etc. ... (BAPTISTA, 1985: 39).

Por outro lado, António Martinho Baptista corrobora a tese avançada por Anati, de que pelo facto de outros suportes antropomórficos terem sido detectados em locais isolados, com carácter supostamente intencional, possam ter assinalado eventuais territórios de caça, ou até domínios sagrados, afastados de áreas agrícolas (BAPTISTA, 1985: 39).

No caso concreto, a estela do castro de Barrega apresenta, como já foi referido, um contexto arqueológico, embora directamente não correlacionado. Os materiais detectados no local da descoberta bem como as características defensivas do mesmo autorizam a definição como sendo um povoado fortificado, não cabendo em nenhuma das duas hipóteses anteriores tidas por clássicas para o tipo de achado em questão. Jean Arnal (1976: 211-221) defende, por seu turno, a possibilidade de alguma desta estatuária ter desempenhado um papel apenas artístico e ornamental no seio de um povoado, tese a considerar, mas que não rejeita uma eventual utilização como marca de território e/ou cipo sinalizador de uma zona de transição planalto/vale, já que as características topográficas conferem ao local da descoberta deste achado um excelente controlo geoestratégico (um amplo controle visual para todos os quadrantes: vale do Tâmega, serras do Marão, Alvão e, parcialmente para o Gerês).

Outros autores propõem, nomeadamente para as estátuas femininas, significados que passam pelo culto da fecundidade ou pelo culto agrícola (ACANFORA, 1960). De facto, a geomorfologia proporcionou a existência de um vale com excelente capacidade agrícola (solos desenvolvidos) e de uma vasta rede hidrográfica, marcando este vale (para Norte) o início do planalto da Lameira, uma área arqueologicamente importante, e com provas artefactuais de significativa actividade agrícola durante a Pré-história recente.

\section{Conclusões}

A estela do castro de Barrega remete para o variado universo de soluções gráficas conhecido no território peninsular, devendo as suas 
características a particularismos endógenos articulados com influências exógenas, que são evidentes.

Relativamente à função e significado deste monumento, julgamos que a resposta, ainda que longe de poder ser alcançada, poderá passar por uma ou pela conjugação de ambas as teses acima apresentadas. Os cenários naturais a que nos referimos parecem concorrer para uma escolha deliberada quanto à implantação deste monumento. A sua cronologia, bem como a da grande maioria das suas congéneres, continuará a suscitar dúvidas, na ausência de um contexto arqueológico fiel.

Apesar das dificuldades na optimização destes dados, a estela antropomórfica de Barrega vem certamente ampliar a valorização do quadro crono-cultural regional e peninsular, bem como reafirmar algumas teses funcionais e cronológicas pelas análises contextuais disponíveis.

\section{Agradecimentos}

Gostaríamos de agradecer à Câmara Municipal de Celorico de Basto pelo apoio no transporte e acondicionamento do monumento, bem como à equipa técnica que auxiliou no seu registo iconográfico (Rosa Jardim, Bruno Figueira, Pedro Gonçalves e Winde Martens). Deixamos ainda expresso o nosso agradecimento ao Departamento de Geologia da Faculdade de Ciências da Universidade do Porto, bem como a Ivone Silva (Geóloga da Câmara Municipal de Celorico de Basto) pelo auxílio na realização do estudo petrográfico do monumento.

Agradecimento especial a António Martinho Baptista, Director do Centro Nacional de Arte Rupestre, pela revisão crítica deste estudo, e a Pedro Gonçalves, pela determinação na aplicação de uma estratégia de conservação do monumento e do incondicional e incansável apoio nos trabalhos a que este se associa, nomeadamente a Carta Arqueológica do concelho de Celorico de Basto.

\section{BIBLIOGRAFIA}

Araúso, Ilídio de (edição de) - Ecos da Montanha. Jornal local de periodicidade mensal. Rego, Celorico de Basto, vários números entre 1963 e 1969.

ARnal, J. (1976) - Les statues-menhirs, hommes et dieux. Ed. des Hespérides, Toulouse. 
Almeida, C. A. F. de; Jorge, V. O. (1979) - A estátua-menir de Faiões (Chaves). Trabalhos do Grupo de Estudos Arqueológicos do Porto, n. ${ }^{\circ}$ 2, Porto.

ACANFora, M. O. (1960) - "Le stelle antropomorfe di Castelluccio dei Sauri". Rivista di Scienze Preistorice, XV (1-4), p. 92-123.

Almagro Basch, M. (1972 - "Los ídolos y la estela decorada de Hernán Pérez (Cáceres) y el ídolo-estela de Tabuyo del Monte (León), Trabajos de Prehistoria, vol. XXIX, Madrid, pp. 83-101.

Almagro Gorbea, M. (1977) - El Bronce Final y el período orientalizante en Extremadura. Biblioteca Praehistorica Hispana, Vol. XIV, Madrid.

Almagro Gorbea, M. (1993) - "Les stèles antropomorphes de la Péninsule Ibérique", 115. Congrès Nationale des Societés Savantes, Avignon (1990), Paris, Éditions du C. T. H. S., p. 123-139.

Baptista, A. Martinho (1985) - "A estátua-menhir da Ermida (Ponte da Barca, Portugal)”. O Arqueólogo Português, série IV, 3, Lisboa, p. 7-14.

Bettencourt, A.; Dinis, A.; Sousa e Silva, I.; Cruz, C.; Pereira, J. (2002) - “A estação arqueológica da Tapada da Venda, Pedroso, Celorico de Basto (Norte de Portugal): primeiras impressões das escavações de 2001”. Portugália, nova série, XXIII. Departamento de Ciências e Técnicas do Património da Faculdade de Letras da Universidade do Porto, p. 187-200.

Bueno RamireZ, P. (1987) - "El grupo Hurdes-Gata en las estelas antropomorfas en Extremadura”. XVIII. ${ }^{\circ}$ Congreso Nacional de Arqueología (Islas Canarias). Zaragoza, p. 449-458.

Bueno Ramirez, P. (1990) - "Statues-Menhires et stèles anthropomorphes de la Péninsule Ibérique”. L'Anthropologie (Paris), Tome 94, n. ${ }^{\circ}$ 1, p. 85-110.

Bueno Ramirez, P. (1991) - "Estatuas-menhir y estelas antropomorfas en la Península Ibérica. La situación cultural de los ejemplares salmantinos”. Del Paleolítico a la Historia, Museo de Salamanca, Junta de Castilla y Léon, p. 81-97

Bueno Ramirez, P. (1995) - "Megalitismo, estatuas y estelas en España". Notizie Archeologische Bergomensi 3. Civico Museo Archeologico, p. 77-129.

D’Anna, A. (1977) - Les Staues-menhirs et Stèles Antrophomorfes du Midi Mediterranéen, Paris, Éditions du C. N. R. S.

Escalon de Fonton, M. (1962) - "Les stèles de Trets". Antiquités Nationales et Internationales, 3 (1-2), pp. 8-12.

Fabregas Valcarce, R. (1991) - Megalitismo del N.O. de la Península. Tipologia y secuencia de los materiales, UNED, Madrid.

Gonzalez Cordero, A.; Alvarado Gonzalo, M. (1986) - "La estela antropomorfa de Salvatierra de Santiago (Cáceres), Studia Zamorensia, vol. VII, Zamora, p. 259-366.

Jorge, Susana O. (1999) - "Stèles et statues-menhires de l'Âge du Bronze en Péninsule Ibérique: discours de pouvoir", L'Europe au Temps d'Ulisses. Dieux et Héros de l'Âge du Bronze, 25 Exposition d'Art du Conseil de l'Europe, AFAA, 114-122. Leroi-Gourhan, A. (dir. de) (1988) - Dictionnaire de la Préhistoire, Paris, P. U. F. PereirA, Eurico (1989) - Carta Geológica de Portugal na escala 1: 50 000. Notícia Explicativa da Folha 10-A: Celorico de Basto. Serviços Geológicos de Portugal, Lisboa. 
Rodriguez Casal, A. A. (1989) - La necrópolis megalítica de Parxubeira, Monografías Urxentes do Museu, 4, La Coruna.

Rodriguez CASAL, A. A. (1992) - "Eléments symbolico-funéraires dans le mégalitisme galicien", Révue Archéologique de l'Ouest, 5, p. 213-221.

SAmpaio, J. D.; FAustino, A. (2002) - "Intervenção de salvamento no sítio de Bolada (Rego, Celorico de Basto)". Revista Portuguesa de Arqueologia, Vol. 5, n. ${ }^{\circ} 1$. Lisboa, p. 29-38.

Silva, Marcos Daniel Osório da (2000) - "Estátua-menir de A-de-Moura (Santana de Azinha, Guarda)”. Estudos Pré-históricos, III, Viseu, p. 229-236.

Sevillano San José, M. C. (1982) - "Un nuevo ídolo de la Edad del Bronce aparecido en Robledillo de Gata (Cáceres)”, Zephyrus, vol. XXXIV-XXXV, Salamanca, p. 165-179.

SeVILlano SAN José (1991) - "Conexiones de las estelas antropomorfas salmantinas y estremeñas. Análisis de nuevos datos para su estudio en la provincia de Salamanca". Del Paleolítico a la História (Santonja, M., ed.), Junta de Castilha y León, Salamanca, p. 96-116.

Silva, Armando C. F. (1986) - A Cultura Castreja no Noroeste de Portugal. Paços de Ferreira. Museu Arqueológico da Citânia de Sanfins. 
EST. I

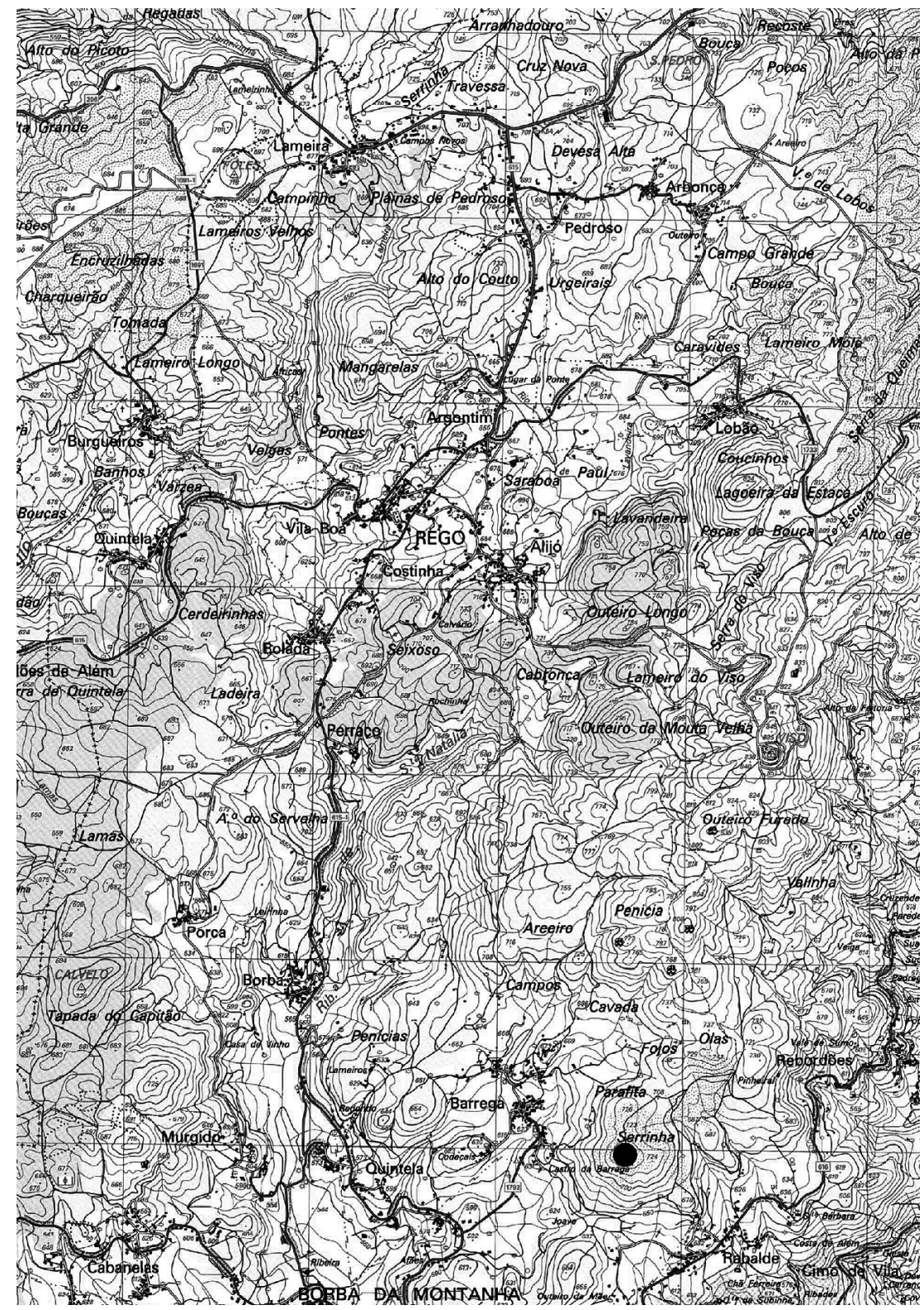

Localização do Castro de Barrega na Carta Militar de Portugal $n .^{\circ} 86$,

à escala 1: 25000. 


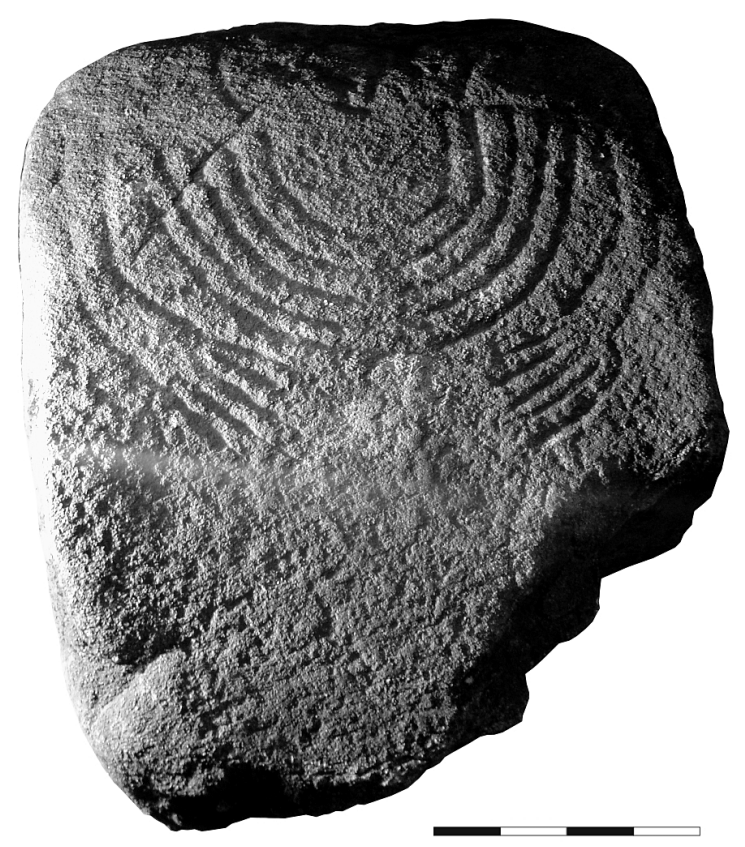

EST. II

FIG. 1 - Estela do Castro de Barrega.

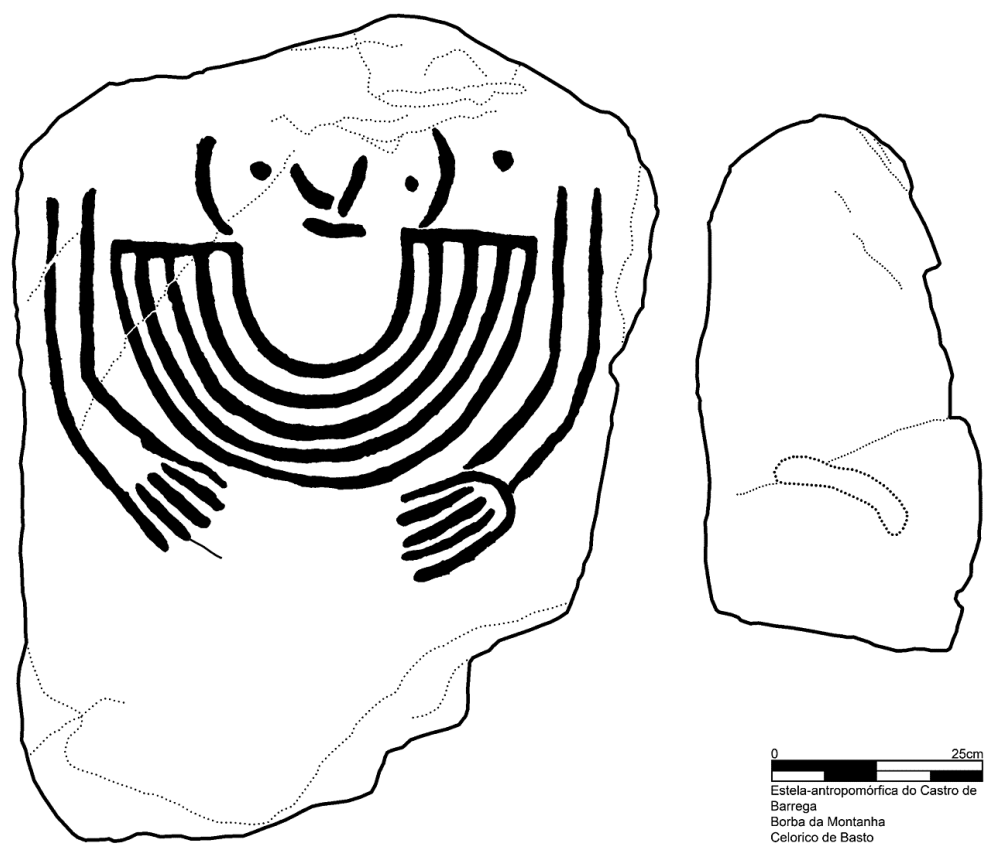

FIG. 2 - Desenho da estela a partir de levantamento à escala de 1:1. 
EsT. III

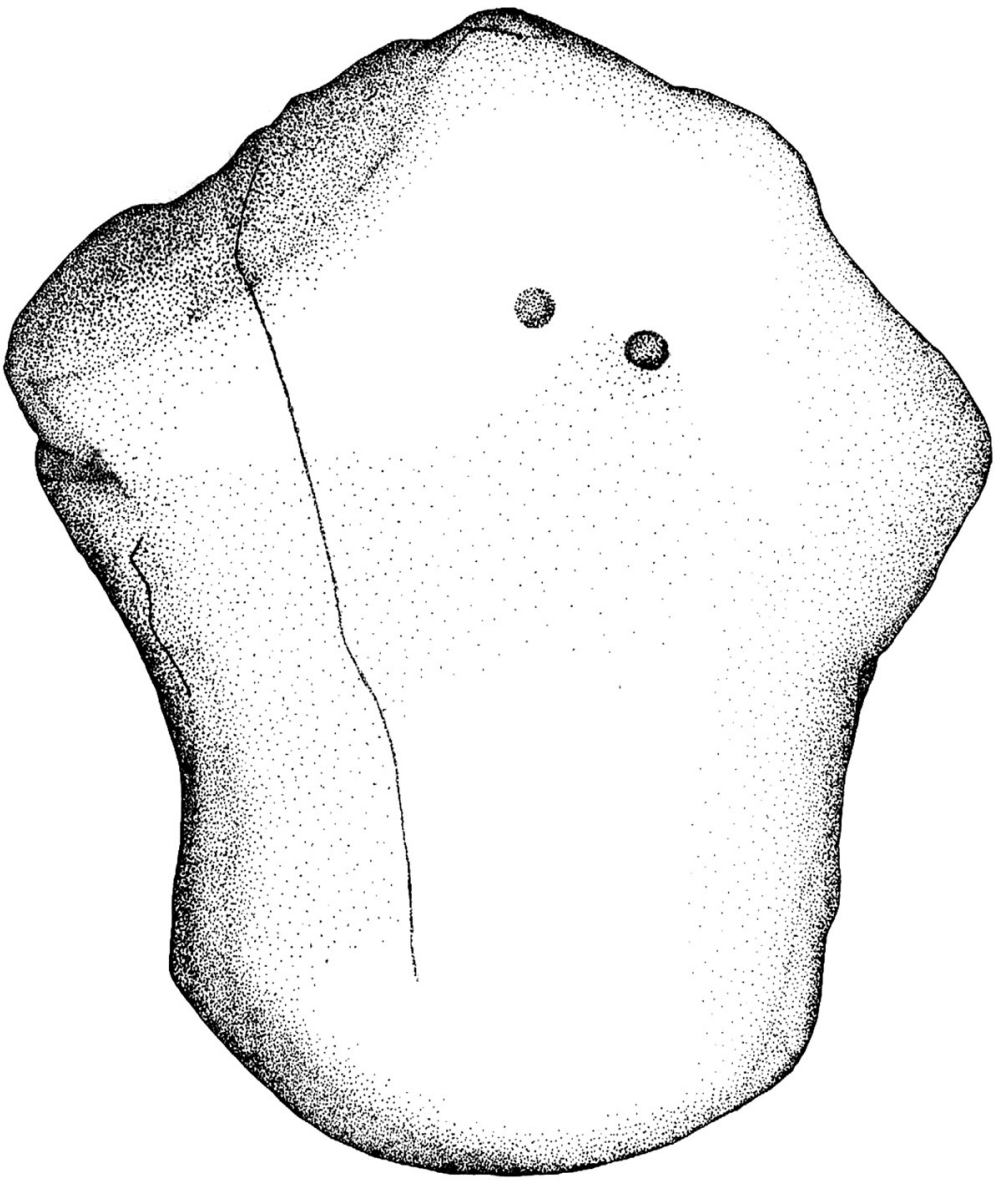

Ídolo antropomórfico da Lameira (Rego, Celorico de Basto). 